\title{
Fundamentals of an Ethics of Care
}

\author{
Giovanni Maio
}

\section{Care: Connecting Virtue and Practice}

The ethics of care, or care ethics, developed in the field of bioethics, primarily in response to the lack of context and the rationalist approach of principlism. Care ethics takes an approach which consciously distances itself from principlism and the idea that ethical problems can be solved by means of abstract principles and instead develops its own concepts. What, then, are the specific characteristics of care ethics? The starting point for the formulation of an ethics of care was undoubtedly the book In a Different Voice (1982) by Carol Gilligan. In this book Gilligan pursues a theory of "two views of morality" and defines care as a specifically female virtue or disposition. Until now care ethics has thus been seen above all in its relation to feminist ethics, raising the issue of the relationship between care and so-called female morals. This restrictive definition in terms of an "ethics of gender" is not of great help in respect of the medical-ethical

G. Maio $(\bowtie)$

Department of Medical Ethics and the History of Medicine,

University of Freiburg, Freiburg, Germany

(C) The Author(s) 2018 
Table 1 Tronto's four-phase model with the corresponding ethical elements of an ethics of care, modified according to Conradi (2001)

\begin{tabular}{ll}
\hline Phases of care & Ethical elements \\
\hline 1. Recognition of need (caring about) & 1. Attentiveness \\
2. Willingness to respond to (take care of) a need & 2. Responsibility \\
3. Direct action (care-giving) & 3. Competence \\
4. Reaction to the care process (of the care receiver) & 4. Responsiveness \\
\hline
\end{tabular}

implications. It seems more important to reflect instead on the basic characteristics of care ethics, for example on the necessity, underlined by Gilligan, of being there for a person in order to realise care, on her emphasis on the network of relationships that binds us to others, and on the primacy of inner judgement and the personal approach, instead of external obligations. Gilligan's radicalised shift of focus to inner judgement and the personal approach provoked direct criticism and brought out alternative voices. For example, the political scientist Joan Tronto understands care not primarily as virtue, but rather as practice (Tronto 1993); she makes it clear that care cannot be achieved through good intentions alone, but can only be considered to have been carried out when these good intentions have actually resulted in some kind of effect on the other person (Table 1). Tronto thus developed a four-phase model of care:

A model such as this is initially illuminating, because it locates care in connection with attitude and action, with outlook and deeds. But such lists (which are not entirely free of trivialities) cannot hide the fact that they are unable to replace theory or methodical reflection. There is a lot to be said for understanding care ethics not so much as a method unto itself but as something that brings a specific point of view to situations and problems. An example of this deeper reflection can be found in Paul Ricœur.

\section{Care According to Paul Ricœur}

In his late work Oneself as Another, Paul Ricœur defines care explicitly as a part of humans' ethical duty. He neatly summarises the content of care when he stresses that care is about being "with the other and for them". 
He thus understands care in one sense as interaction with the other and at the same time as referring to them. This double reference brings together the two essential aspects of care. Drawing on the Aristotelian concept of friendship, Ricœur focuses on the fact that care is grounded in reciprocity. He thus categorically rejects Emmanuel Levinas' one-sided appeal to care that extends from the other to us, underlining the reciprocity of the care relationship. Care is not oriented in one direction towards the person who receives care. The person providing care also changes as a result. By confronting the unfamiliarity of the care receiver, the care provider expands their own horizons. It is thus care that enables them to find their own identity in unfamiliarity. In care, what was previously seen as self-evident as well as one's view of the world and the self-made onesided through routine-are broken down and exposed. According to Ricour, care has a mediating function in that the care provider, in order to really show care, must enter "foreign ground", become distanced from themself, in order to be able to broaden their own standpoint and vantage point. ${ }^{1}$ Ricour thus makes an original connection which goes beyond the link between care and finding one's personal identity to also connect care to the valuable asset of self-esteem: our image of ourselves is formed above all through dialogue with others. By providing care for the other, our own self gains a layer of unfamiliarity, which helps us not only to see ourselves more clearly but also to value ourselves more. At the same time, for Ricœur, caring is always linked to a recollection of our own vulnerability, and this reminder, in which we experience ourselves as being "related" to the person in need of help, triggers a process of change in the giver. Thus through the simple fact of making their need for help known, the care receiver becomes the giver by opening up the care provider to experiences that would otherwise have been denied to them. The awareness of being "related" or "similar" (as Ricœur also says) to the person receiving care, in connection with the fundamental attitude that there is a "reversibility" of the roles in the provision of care, leads to an effort to compensate for the obvious asymmetry and create equality. For Ricœur, care is thus a crucial motivator in the "search for equality in the midst of inequality" (Ricœur1992, p. 192). It represents a call for increased equality, for the abolition of one-sided thinking, and for the facilitation of reciprocity. In pursuing these goals, an inner identification 
with the other and "the shared admission of fragility" are needed (Ricœur1992, p. 192).

For Ricœur, care is thus a reciprocal phenomenon, because it is only realised when a response is given - that is through the reference to a demand - which in turn depends on active questioning and on a response supported by kindness and consideration. Ricœur describes this response to the other's requirement as a fundamental willingness, "by which the self makes itself available to others" (Ricœur1992, p. 168). He also defines this process of making oneself available and the related openness to the particular nature of the other as a disposition to kindness (Ricœur 1992, p. 189). This disposition lies at the heart of care. The other can initiate a new situation and self-esteem, so long as the care provider is sensitive to the demand that they have made. Ricœur calls the acceptance of the associated responsibility "striving for the good of the other".

At one point, Ricour also expresses this conception of care in connection with the concept of "benevolent spontaneity", making it clear that care is an interaction which must be supported by a certain fundamental disposition: the disposition of goodwill. Ricœur thus links his conception of care back to motivational contents and emotional factors which present themselves in the immediacy of the interaction with the person in need of care. Care is hence conceived of as a combination of (1) reflexivity (self-awareness), (2) intentionality (being oriented towards the other), (3) affectivity (goodwill), and (4) spontaneity (immediacy).

\section{Systematics of the Core Elements of an Ethics of Care}

Now that we have drawn on Paul Ricœur to discuss one of the most wellfounded conceptions of care, our focus will turn to developing a more general understanding of care ethics. We have seen that there certainly are differing conceptions, but, all differences aside, a closer look reveals some underlying characteristics which can shed light on the particular nature of care ethics. 


\section{Anthropology of Dependence}

A central feature of care ethics is the anthropology on which it is based. This anthropology was originally developed as a counterreaction to a form of ethics that (like the principlism described here) focuses on the individual as a sovereign being with the right to selfdefence. Care ethics does not, of course, negate the need to respect these rights, but rests upon a different view of humanity. Rather than on the sovereignty of each individual, it focuses on their fundamental dependence. Practising care ethics means recognising that each individual lives within a basic structure of dependence, whether or not they are conscious of this dependence (which was also Gilligan's basic idea). Care ethics thus takes as its point of departure an awareness of the asymmetry of the situation in which people in need of help or care find themselves. Their situation is not so much based on reciprocity but on a reflection of a fundamental state of dependence inherent to all human beings. And it is also this situation that makes care necessary as a form of action constituting a response to this fundamental trait of dependence. What distinguishes care ethics, however, is not just that it acknowledges asymmetry and thus dependence. It also frees this dependence from its negative connotations: from the perspective of care ethics, needing help is not considered an imperfection, but rather something normal and generally paradigmatic for relationships.

In this context, asymmetry does not refer to the cementing of a benevolent paternalism. Instead, it concerns the recognition that although the situation may be one of inequality, this does not negate the postulate of an equal level of respect and of equality between people. In other words, an ethics of care acknowledges the different degrees of sovereignty that a person may have in their particular situation, but without relativising on any level the fundamental equality of all humans in their moral rights and relationships of recognition. Its ultimate aim (as we saw with Ricœur) is instead, at the same time, to balance out the asymmetry of sovereignty by means of the equality of the people involved. 


\section{Being in Relationships}

Relationships play a crucial role in care ethics in three regards. Firstly, they are based on a concept of anthropology that does not just perceive humans as dependent beings but also interprets them as beings oriented towards relationships with other humans. Relationships are a fundamental feature of human existence. Secondly, relationships are seen as playing a significant role in the development of ethical problems, particularly with regard to a lack of relationships. For care ethics, relationships thus become a prism through which to view ethical problems. Finally, relationships are also a crucial strategy for resolving such conflicts. Against this background it is clear why care ethics makes reference to the crucial importance of human connectedness in resolving ethical problems. This relational approach to ethics also involves an appreciation of other virtues that have a stabilising effect on relationships, such as forbearance and forgiveness or devotion and trust. Care ethics thus places significantly more value on affective connections and prioritises interactive actions for resolving ethical conflicts.

However, since promoting relationships as a solution to every problem would not be appropriate either, a nuanced approach is required here. It is not unusual for the entanglement in relationships itself to cause problems for patients, for example when they find themselves in a situation of dependence and need help extracting themselves in order to resolve the problem. For the people providing help, this focus on relationships is also always a balancing act, since they must guard against becoming too emotionally involved and ultimately burning themselves out. This is where we begin to see the limits of expecting too much of relationships when it comes to providing solutions. Nonetheless, the emphasis on the moral dimension of relationships and the appreciation of virtues which make relationships more stable are two of the crucial elements at the heart of an ethics of care.

\section{Being Situation-Oriented}

A key issue with regard to care ethics is that of the reason or justification for a particular action or reaction. While principlism adopts a deductive 
approach here, deriving action from abstract principles (and justifying it by way of these principles), care ethics takes a fundamentally different path. Rather than basing its actions on an abstract rule and moving from here to practice, it takes practice itself as the foundation for selecting the action required. It thus does not follow a deductive model, but instead sees the immediacy and singularity of a particular situation as an instruction to decide on the action that seems most appropriate in that situation. Thus, while principlism applies rules, care ethics is concerned with a fitting response that must be developed based on the situation, since the specific nature of a situation cannot be confronted adequately simply by applying rules. This shows that, in terms of method alone, care ethics is not concerned with the criterion of generalisability or with a Kantian idea of universalism; rather, it focuses on understanding the particular and incomparable nature of the patient and their situation. Generalisability is replaced by singularity and particularity. This is reminiscent of hermeneutic ethics insofar as the particular point of view of care ethics lies specifically in inquiring into the particular and thus the unique nature of the other. It is therefore no coincidence that the hermeneutist Ricœur of all people advocates an ethics of care, nor thatdrawing on the Aristotelian concept of phronesis-he identifies "practical wisdom" as the methodical basis for ethical judgements. Ricœur wanted care to be understood as a guarantee that the unique nature of the other is protected against being taken over by generalising postulates. He sees the fundamental role of care in saving the otherness of the other.

In summary, this aspect of situational specificity can be divided into three elements:

(a) emphasis on immediacy and acknowledgement of immediate perception

(b) recognition of the singularity of the situation

(c) need for a creative resolution to conflict rather than one that is simply rule-based.

Care ethics thus represents a progressive alternative to simple instrumental rationality. 


\section{Responsiveness}

In the light of the above, the distinguishing feature of care ethics is that it is defined less by initiative than by responsiveness. It responds or reacts to the needs of the person who is dependent on help. Care ethics is primarily response-focused. It is the other who calls for care. Thus care ethics is linked to the attitude and gestures of "turning to" somebody and necessitates the capacity to approach the other. This requires an attitude of listening, of receptiveness, of understanding, essentially of close attention. Here, too, we can see a similarity with hermeneutic ethics, although care ethics involves more than just understanding; it contains the impulse to change, to realise care (Maio 2015). This impulse to realise care can be understood as the impulse to implement the response we are urged to give by the urgent situation of the other. In this context, Emmanuel Levinas defined care as "being called on" by the other.

\section{Accepting the Indefinable}

As care ethics does not aim to be rule-based and instead takes the specific situation as its point of departure, the demand made on the result of the ethical judgement is also entirely different. Ethics based on deductive reasoning demands exactitude and unambiguousness, following the motto: Is this permitted or not permitted? Required or not required? Right or wrong? Care ethics does not apply these categories, which constitutes another similarity with hermeneutic ethics. Instead, it is characterised by a tolerance for ambiguity; as it takes seriously the specific features of each situation, it cannot predict what is right and what is wrong. A situation may remain ambivalent until the last moment. But care ethics does not see ambivalence as a state that should be abolished by any means-paying attention to, allowing and bearing ambivalence are part and parcel of the methodical approach of an ethics of care. In other words: from the epistemology of particularity comes an acceptance of ambiguity. There is no one correct solution, but rather a spectrum of solutions; there is no single right answer, but rather what is appropriate 
in each case, and there is also no objective solution that is connected with a universalistic pretension. Instead, it is a case of the particular and thus the always fallible.

\section{Giving Preference to Emotional Knowledge}

The above criteria show that care ethics differs from other forms of ethics above all in the way in which problems are perceived. It perceives the ethical problem in different terms, which are not just related to the above basic elements, but rest more fundamentally on a wider concept of knowledge. For care ethics, knowing the objectifiable and formalisable facts does not suffice; care ethics also draws on what could be called "implicit knowledge". The critical role of relationships, the demand for an adequate perception of the situation, and the prioritising of creative solutions over deductive inference necessitate implicit forms of knowledge such as experiential knowledge, situational knowledge, and relationship knowledge. Valuing these forms of knowledge, which go beyond the confines of a formal-logical approach, is the essence of care ethics. They are forms of knowledge that cannot be learnt by heart but must be practised. According to care ethics, competence could be described as skill in dealing with ambiguity. The ability to cope with complexity plays a significantly more constitutive role here than in other forms of ethics. This perhaps also explains why the medical community continues to give little importance or support to care ethics. Care ethics represents a counterpoint to operational rationality because it practices a rationality of its own, in which feelings, intuition, and sensations are just as important as calculations, and in which experience is ascribed an epistemological value which is overlooked in the structural logic of modern medicine.

In this regard, care ethics is more progressive than many forms of principlism, because it does away with the prejudice of the irrationality of feeling, because it takes the knowledge content of feelings seriously and in this respect constitutes an implicit plea to place more value on emotional knowledge. The specific challenge of care ethics, on the other hand, 
is to take this emotional knowledge seriously in such a way that it is not set in opposition to cognitive knowledge. A healthy balance must be struck between both forms of knowledge, placing more value on emotional knowledge as a creative factor while cognitive knowledge remains present in the same way as a constant check and balance. Care ethics can only truly bear fruit when it draws on emotional knowledge to enable unique and creative approaches without being absolved of the obligation to justify such creative solutions with transparent and comprehensible arguments.

\section{Giving Preference to Space for Growth}

Care ethics does not just expand the above-described form of knowledge and insights; its core elements also open up an alternative view of how to deal with ethical problems. Where the focus of care ethics lies in perceiving the complexity of an ethical problem, and where this complexity or ambiguity necessitates a more receptive approach, the response to the problem will also be evaluated using entirely different criteria than those used when focusing on structural functionality. There is a similarity to hermeneutic ethics here in that it is not rapid, confident action that counts, but rather a tentative and considerate approach. This entails a different definition of good actions, one where the guiding values are careful reflection and prudence. It was Carol Gilligan herself, the initiator of the care ethics debate, who emphasised hesitation and tentative consideration as indicators of care, and, as we saw above, Paul Ricœur also talks explicitly of consideration. Precisely because care ethics assumes that there are no unambiguous solutions, it attributes more value to doubt; the attitude of tentative hesitation has no trace here of the negative connotations that are necessarily attached to it in the constant bustle of large medical institutions. This confers on care ethics nothing short of a subversive power in relation to action as well. This subversive power can be extremely restorative because it can give rise to the insight that good medicine means not simply doing things but also allowing these things space to thrive. This praxeology of caution could make it possible to rediscover 
the value of giving things space to thrive, to mitigate the tendency towards actionism, and to introduce a way of thinking that makes a clearer distinction between medicine (as care) and industry (as production site).

\section{Limits of Care Ethics}

It has become clear that care ethics renounces a universalistic pretension and instead turns towards the unique and the particular. It thus constitutes a necessary correction to the prevalent hegemony of the structuralfunctional approach. However, renouncing universalistic pretensions inevitably raises the objection that care becomes arbitrary and relative. This reproach can only be refuted by making it clear that individual decisions are taken within a predefined framework, which is not invalidated by the particularity of a situation but remains in place as a constitutive framework.

A second criticism has already been discussed above. The fundamental significance that care ethics attributes to relationships and attention also has the potential, in some situations, to place excessive demands both on the treatment team and on the patient. Sometimes a patient has no desire to enter into a relationship, but simply wants to make use of a service. This objection can be fundamentally rejected using care ethics itself, since an ethics of care, understood correctly, should take its specific starting point seriously in such a way that in the case of doubt it recognises that a particular situation requires a distanced approach based more on principlism or ethics of ought. This highlights once again the fact that care ethics represents a very particular approach to ethical problems which cannot and should not be the most appropriate solution to all situations and medical-ethical problems. Care ethics is only as good as the way in which it is applied. It will only be beneficial when it is applied to problems for which it is the most suitable method. In contrast, attempts to elevate it to the level of a medical-ethical paradigm will inevitably result in shortcomings, not in care ethics itself but in the diligence that is applied when choosing it as the method to be used in specific contexts and situations. 


\section{Conclusions}

Care ethics developed as a reaction to the one-sided thinking of principlism and duty ethics or, as it is sometimes called, ethics of justice. This context has induced polarisation which obscures the fact that both care ethics and principlism are needed. They are not alternative models; they must be allowed to complement one another. In order for medicine to do justice to a patient, there must be an awareness of principles and basic rights and of the significance of a principle as abstract as that of human dignity. That much is indisputable. But on its own it is no guarantee that the patient will truly be helped. In order to help the patient in their specific situation, it is necessary to take a highly individualised approach and develop a strategy that will really help that person. Such a strategy cannot be reduced to adapting rules or limited to subjective arbitrariness. It demands an individual approach to a specific person within a predefined framework. The value of care ethics lies its assumption that the dependence of the other demands the personal acceptance of responsibility. This acceptance of responsibility (the crucial role of the "response" should be borne in mind here) goes beyond ensuring basic rights.

Care ethics, whose core aspects we have highlighted above, thus enriches ethics, makes it more stimulating, and brings to it greater substance that cannot easily be codified. But the specific richness of this substance can only fully develop when it is firmly located within a fixed framework of principles which is not in opposition to care ethics but on the contrary is what finally enables care ethics to be realised. Paul Ricœur neatly summarises this complementary relationship when he emphasises that the power of judgement which is so crucial for care "consists in inventing conduct that will best satisfy the exception required by solicitude, by betraying the rule to the smallest extent possible" (Ricœur 1992, p. 269).

\section{Note}

1. Axel Honneth takes a similar approach when, referring to the granting of care, he formulates the possibility of a "decentred perspective" (Honneth, 1996, p. 74). 


\section{References}

Conradi, E. (2001). Take Care. Grundlagen einer Ethik der Achtsamkeit. Frankfurt am Main: Campus.

Gilligan, C. (1982). In a Different Voice. Harvard: Harvard University Press.

Honneth, A. (1996). The Struggle for Recognition: The Moral Grammar of Social Conflicts. Cambridge: The MIT Press.

Maio, G. (2015). Den kranken Menschen verstehen. Für eine Medizin der Zuwendung. Freiburg: Alber.

Ricœur, P. (1992). Oneself as Another. (K. Blamey, Trans.). Chicago: University of Chicago Press.

Tronto, J. C. (1993). Moral Boundaries: A Political Argument for an Ethic of Care. London: Routledge.

Open Access This chapter is licensed under the terms of the Creative Commons Attribution 4.0 International License (http://creativecommons.org/licenses/ by/4.0/), which permits use, sharing, adaptation, distribution and reproduction in any medium or format, as long as you give appropriate credit to the original author(s) and the source, provide a link to the Creative Commons license and indicate if changes were made.

The images or other third party material in this chapter are included in the chapter's Creative Commons license, unless indicated otherwise in a credit line to the material. If material is not included in the chapter's Creative Commons license and your intended use is not permitted by statutory regulation or exceeds the permitted use, you will need to obtain permission directly from the copyright holder.

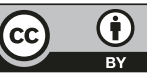

